\title{
EL ASUNTO DE LA OBLIGACIÓN DE NEGOCIAR UN ACCESO AL OCÉANO PACÍFICO. COMENTARIO DE LA SENTENCIA DE LA CORTE INTERNACIONAL DE JUSTICIA, DE FECHA 1 DE OCTUBRE DE 2018
}

\author{
THE CASE ON THE OBLIGATION TO NEGOTIATE AN ACCESS TO \\ THE PACIFIC OCEAN: CASE-NOTE ON THE JUDGMENT OF THE \\ INTERNATIONAL COURT OFJUSTICE, DATED 1 OCTOBER 2018
}

\section{Sebastián López Escarcena*}

RESUMEN: La sentencia de fondo en el asunto de la obligación de negociar un acceso al Océano Pacífico le puso fin a una aventura judicial que Bolivia comenzara cinco años antes en contra de Chile. Esta no solo resume más de un siglo y medio de intercambios diplomáticos entre ambos estados, sino que los analiza desde la perspectiva del derecho internacional. Poco se innovó en este fallo respecto de tratados, actos unilaterales y comportamientos recíprocos de los estados. Más interesante es la reiteración que hizo el tribunal de las obligaciones de medios y de resultado, por un lado, y de los acuerdos tácitos, por otro. Esta sentencia, sin embargo, marca un antes y un después en las relaciones boliviano-chilenas, y pasa a constituir un verdadero tour de force de su evaluación jurídica.

Palabras clave: Corte International de Justicia; obligación de negociar; tratados; actos unilaterales; comportamientos recíprocos

\begin{abstract}
The judgment on the merits of the case on the obligation to negotiate an access to the Pacific Ocean put an end to a judicial adventure that Bolivia started five years before against Chile. It not only resumes more than a century and a half of diplomatic exchanges between both states, but also analyses them from the perspective of international law. Little is new in this judgment with respect to treaties, unilateral acts and reciprocal behaviour of states. More interesting is the reiteration made by the tribunal of the obligations of means and of result, on one side, and of tacit agreements, on the other. This decision, however, marks a turning point in the Bolivian-Chilean relations, and constitutes a veritable tour de force of its legal evaluation.
\end{abstract}

Keywords: International Court of Justice; obligation to negotiate; treaties; unilateral acts; reciprocal behaviour.

\footnotetext{
Profesor asociado de la Facultad de Derecho de la Pontificia Universidad Católica de Chile, e investigador asociado (associate fellow/membre associé) del Centro para el Estudio de la Gobernanza Global de la Universidad Católica de Lovaina, Bélgica, y del Instituto de Investigación en Derecho Internacional y Europeo de la Universidad de París 1 "Panthéon-Sorbonne", Francia. PhD (Edimburgo), LLM (Leiden), Abogado y Licenciado en Derecho (Católica de Chile). Dirección postal: Alameda 340, Edificio de Derecho, 8331150, Santiago de Chile. Correo electrónico: rlopeze@uc.cl
} 


\section{INTRODUCCIÓN}

El 1 de octubre de 2018, un demudado Evo Morales terminaba de escuchar la lectura que el juez Abdulqawi Ahmed Yusuf hacía de la sentencia de la Corte Internacional de Justicia, recaída en el asunto de la obligación de negociar un acceso al Océano Pacífico. El contraste entre la expresión del presidente de Bolivia y el triunfalismo exhibido por la delegación de ese país unos minutos antes, no podía ser mayor. Cuando en 2015 el tribunal aceptó tener competencia para resolver este caso, muchos interpretaron la decisión sobre excepciones preliminares como una especie de prejuzgamiento de lo solicitado en el fondo por Bolivia ${ }^{1}$. En un lapidario fallo, la Corte resolvió tres años después que Chile no había contraído obligación alguna con el estado demandante ${ }^{2}$. Con su sentencia, el tribunal dio cuenta de más de un siglo y medio de negociaciones entre ambos estados. Descartando posibles tratados, actos unilaterales, estoppel y aquiescencia, esta sentencia puso fin de forma abrupta a toda una época en las relaciones bilaterales boliviano-chilenas, marcada por un negacionismo victimista, de un lado, y la reticencia a modificar el statu quo, del otro. En 177 párrafos, el tribunal se refirió a la guerra que enfrentó a Chile con Bolivia y Perú entre 1879 y 1884; a los tratados que celebró Bolivia con Chile en 1895, y que nunca entraron en vigor; al Tratado de Paz y Amistad de 1904, vigente desde ese año; a ciertas iniciativas diplomáticas de los años 20; al intercambio de notas entre Bolivia y Chile de 1950; al proceso de Charaña de los 70; a ciertas resoluciones de la Organización de Estados Americanos (OEA); a las negociaciones boliviano-chilenas de la década de 1980; y a aquéllas que tuvieron lugar entre las partes litigantes a principios de este siglo. El siguiente comentario hace un breve recuento del proceso ante la Corte en este caso, de los presupuestos con los que esta comenzó su análisis de la controversia, de cada una de los momentos en que Chile supuestamente contrajo una obligación de negociar una salida soberana al mar para Bolivia, y de la evaluación que hizo el tribunal de estos episodios, para terminar con una breve explicación de la importancia de esta sentencia para el derecho internacional, y de las causas y consecuencias de la derrota boliviana.

\section{JUDICIALIZANDO LA HISTORIA}

El capítulo cuarto, título VIII, de la Constitución Política de Bolivia se denomina "Reivindicación marítima” y tiene solo dos disposiciones. Una de estas es el Artículo 267, que establece para Bolivia un "derecho irrenunciable e imprescriptible sobre el territorio que le dé acceso al Océano Pacífico y su espacio marítimo”. Como agrega esta disposición, "[1]a solución efectiva al diferendo marítimo a través de medios pacíficos y el ejercicio pleno de la soberanía sobre dicho territorio constituyen objetivos permanentes e irrenuncia-

\footnotetext{
1 Ver en general BoLIVIA C. CHILE (2015).

Sobre esta decisión judicial ver Lagos Erazo (2016) pp. 119-82; y Errázuriz y Neri (2019) pp. 34-62. Ver en general López EsCARCENa (2016).

2 Ver Bolivia C. CHILE (2018) párrafo 177.

Las decisiones judiciales de la Corte están disponibles francés e inglés en: <https://www.icj-cij.org/en/list-of-allcases> [fecha de consulta: 1 de abril de 2020]
} 
bles del Estado boliviano"3. Esta constitución fue promulgada en 2009 por Evo Morales, el mismo presidente de Bolivia que el 24 de abril de 2013 presentó una solicitud contra Chile ante la Corte Internacional de Justicia, pidiéndole que declare la existencia e incumplimiento de su obligación de negociar un acceso soberano al Océano Pacífico, que es el nombre que le dio el tribunal a este asunto ${ }^{4}$. Bolivia hizo llegar su memoria el 17 de abril de ese año ${ }^{5}$. Chile, en tanto, interpuso el 15 de julio de 2014 una excepción preliminar en la que objetó la jurisdicción de la Corte, provocando la suspensión del procedimiento. Bolivia presentó por escrito sus observaciones y conclusiones respectivas el 14 de noviembre de $2014^{6}$. Las audiencias públicas sobre la objeción preliminar tuvieron lugar entre el 4 y el 8 de mayo de 2015. El tribunal rechazó la excepción interpuesta por Chile el 24 de septiembre de 2015, resolviendo tener jurisdicción para conocer el caso en base a lo dispuesto en el Artículo XXXI del Pacto de Bogotá de 19487. En su decisión, la Corte señaló que el objeto de la controversia consiste en establecer si Chile tiene una obligación de negociar de buena fe un acceso soberano al Océano Pacífico para Bolivia, y si incumplió este deber, en caso de tenerlo ${ }^{8}$. El tribunal distinguió entonces el fin último buscado por el estado demandante (acceso soberano al Océano Pacífico), de lo solicitado concretamente en este caso (obligación de negociar de buena fe) ${ }^{9}$. Al respecto, la decisión sobre excepción preliminar declaró expresamente que, de llegar a establecerse este deber del estado demandado, "no le corresponderá a la Corte predeterminar el resultado de cualquier negociación que tenga lugar como consecuencia de dicha obligación” ${ }^{10}$. El 25 de julio de 2016, Chile presentó su contra-memoria ${ }^{11}$. La réplica de Bolivia y la dúplica de Chile fueron ingresadas a la Corte el 21 de marzo y el 21 de septiembre de 2017, respectivamente ${ }^{12}$. Las audiencias sobre el fondo del caso de Bolivia contra Chile se realizaron entre el 19 y el 28 de marzo de $2018^{13}$. En sus escritos y alegatos, Bolivia solicitó a la Corte que declare que Chile tiene una obligación de negociar para llegar a un acuerdo que le otorgue un acceso al Océano Pacífico, que ha incumplido este deber, y que debe cumplirlo "de buena fe, pronta y formalmente [...], y de manera efectiva": vale decir, "en un plazo razonable" y que dicho acuerdo le otorgue un

\footnotetext{
3 Ver Errázuriz y Neri (2019) pp. 17-8.

4 Ver Bolivia C. CHILE (2018) párrafo 1.

Sobre los antecedentes diplomáticos de la solicitud de Bolivia ver DurÁn (2013 sentencia) pp. 229-77; LAGOS Erazo (2013) pp. 33-88; Rodríguez Elizondo (2014) pp. 105-93; Rodríguez Guarachi (2015); Lagos Erazo (2016) pp. 75-117; Rodríguez Elizondo (2016) pp. 117-31; y Errázuriz y Neri (2019) pp. 15-27.

5 Ver Bolivia C. CHILE (2018) párrafo 4.

${ }^{6}$ Ver Bolivia C. CHILE (2018) párrafo 6.

Ver Bolivia C. ChILe (2018) párrafo 8. Ver también Bolivia C. CHILE (2015) párrafo 56.

8 Ver BoliVia C. ChILE (2015) párrafos 27, 31 \& 34.

9 Ver Bolivia C. CHILE (2015) párrafos 32-3.

10 Bolivia C. Chile (2015) párrafo 33. Ver López Escarcena (2016) pp. 716-7.

11 Ver Bolivia C. CHILe (2018) párrafo 9.

12 Ver Bolivia C. CHILE (2018) párrafo 10.

13 Ver Bolivia C. Chile (2018) párrafos 11-2.
} 
acceso "plenamente soberano" 14 . En los suyos, Chile simplemente le pidió al tribunal que "desestime todas las demandas" de Bolivia ${ }^{15}$.

La Corte dictó su sentencia en este caso el 1 de octubre de 2018. A pesar de haber resuelto en 2015 tener jurisdicción para conocer esta controversia en virtud del Pacto de Bogotá, el tribunal hizo diversas aseveraciones sobre la historia de Bolivia y de Chile que antecedieron con mucho a la fecha de entrada en vigencia de este tratado ${ }^{16}$. Quizás la razón para esto haya sido fortalecer la conclusión final a la que llegó el tribunal en esta controversia, en el sentido de dar a entender que Chile nunca contrajo una obligación de negociar con Bolivia una salida soberana al mar, en todo el período posterior al término de la Guerra del Pacífico ${ }^{17}$. Como en su decisión sobre excepción preliminar, la sentencia de fondo de la Corte volvió a insistir en que Chile le declaró en 1879 la guerra a Bolivia y Perú, lo cual no solo es incorrecto sino que además es simplista, pues reduce un conflicto armado complejo como la Guerra del Pacífico a una narrativa dual que va acompañada de un reproche moral implícito en contra del supuesto agresor, que favorece por tanto a los presuntos agredidos ${ }^{18}$. Esta relectura parcial que ha hecho el tribunal de la Guerra del Pacífico se viene arrastrando desde su sentencia de 2014, recaída en la disputa marítima (Perú c. Chile $)^{19}$. A diferencia de ese caso, dicha aseveración histórica no tuvo una consecuencia jurídica en el asunto de la obligación de negociar un acceso al Océano Pacífico. Esta sentencia también hizo referencia a los tratados que celebraron Bolivia y Chile en 1895, que fueron tres: un Tratado de Paz y Amistad; un Tratado de Transferencia de Territorio; y un Tratado de Comercio. Sobre el segundo de estos, la Corte explicó que las partes acordaron que los territorios entre Arica y Tacna serían transferidos a Bolivia si Chile adquiría su soberanía "ya fuese por negociaciones directas o por el plebiscito previsto en el Tratado de Ancón de 1883 [celebrado con Perú]" ${ }^{20}$. En caso que Chile no adquiriese dichos territorios, el mismo tratado de transferencia disponía que le cedería a Bolivia una franja de territorio

\footnotetext{
14 Bolivia C. Chile (2018) párrafos 13-5.

15 Bolivia C. CHILE (2018) párrafo 14-5.

Los escritos y alegatos de las partes litigantes en este caso, así como la sentencia de la Corte, están disponibles en inglés y francés en: <https://www.icj-cij.org/en/case/153> [fecha de consulta: 1 de abril de 2020]

Se han publicado resúmenes de dichos escritos y alegatos.

Ver, e.g., Errázuriz y Neri (2019) pp. 15-7, 19-21, 38-52, 54-9, 71-93 \& 97-107.

16 Ver López Escarcena (2016) pp. 719-20. Ver López Escarcena (2016) pp. 722-4.

Sobre el Tratado Americano de Soluciones Pacíficas de 1948 ver en general Valencia-Ospina (2011); Infante (2016); e InFANTE (2017).

17 En cuanto a la Guerra del Pacífico o Guerra del Salitre ver en general Cluny (2000); Farcau (2000); y Sater (2007).

18 Ver Bolivia c. Chile (2018) párrafo 21. Ver también Bolivia C. Chile (2015) párrafo 16.

Respecto a este punto, ver Cluny (2000) pp. 136-56; FARCAU (2000) pp. 31-46; y SATER (2007) pp. 27-43.

19 Ver Perú C. ChILE (2014) párrafo 17. Ver también López Escarcena (2016) pp. 724-5.

Sobre el caso de Perú con Chile ver en general López Escarcena (2014).

20 Ver Bolivia C. CHILe (2018) párrafo 22.
} 
ubicada al sur de Arica ${ }^{21}$. Estos tratados de 1895 requerían la aprobación del protocolo aclaratorio del mismo año por parte de los congresos nacionales de Bolivia y Chile, lo que no ocurrió, por lo que nunca entraron en vigor $^{22}$. La sentencia de la Corte se refirió, asimismo, al Tratado de Paz, Amistad y Comercio entre Bolivia y Chile de 1904, por medio del cual el primero reconoció la soberanía del segundo sobre el territorio ocupado desde $1879^{23}$. Esto es, sobre el antiguo Departamento del Litoral de Bolivia, cuyo gobierno por Chile había sido aceptado ya en el Pacto de Tregua de $1884^{24}$. En el Tratado de 1904, Chile se comprometió además a construir un ferrocarril entre Arica y La Paz; a conceder perpetuamente a Bolivia un derecho de libre tránsito comercial "por su territorio y puertos del Pacífico"; y a permitir la constitución de agencias aduaneras bolivianos en los puertos ahora chilenos de Arica y Antofagasta ${ }^{25}$.

El recuento histórico de la Corte, sin embargo, fue más detallado respecto de los intercambios diplomáticos boliviano-chilenos que se sucedieron entre la década de 1920 y la de 2010, que es donde el tribunal centró su análisis histórico y jurídico, el cual conviene revisar en conjunto, a pesar de haberlo presentado el tribunal en forma separada en su fallo ${ }^{26}$.

\section{PRIMERAS CONVERSACIONES EN LA DÉCADA DEL 20}

Ya en 2015 la Corte había determinado que el objeto de esta controversia consiste en establecer si Chile se obligó a negociar de buena fe con Bolivia un acceso soberano al Océano Pacífico, por un lado, y aclarado que "esta supuesta obligación no incluye un compromiso de alcanzar un acuerdo sobre el objeto de la controversia", por otro ${ }^{27}$. Como explicó en su sentencia de 2018, en la decisión sobre excepción preliminar quedó resuelto que Bolivia no solicita que se declare que tiene derecho a un acceso soberano al Océano Pacífico, sino que pide que se falle que Chile se encuentra obligado a llegar a un acuerdo que le otorgue dicho acceso ${ }^{28}$. Con relación a este punto, la sentencia recordó la interpelación que le hiciera el juez Hisashi Owada a Bolivia en los alegatos de la excepción preliminar, y la respuesta de $\operatorname{esta}^{29}$. Antes de resolver si Chile contrajo en algún momento dicha obligación

\footnotetext{
${ }_{21}$ Ver Bolivia C. CHILE (2018) párrafo 23.

En cuanto a los tratados de 1895 entre Bolivia y Chile ver Bustos (2004) pp. 94-8; Pinochet de la Barra (2004) pp. 21-7; Figueroa (2007) pp. 22-30; Lira (2009) pp. 152-8; Lagos Erazo (2014) pp. 127-30; Lagos Erazo (2016) pp. 187-9; y Bustos (2018) pp. 197-204. Ver en general Concha (2011).

22 Ver Bolivia C. CHILE (2018) párrafo 24.

23 Ver Bolivia C. CHILE (2018) párrafo 25.

24 Ver Bolivia C. Chile (2018) párrafo 22.

25 Ver Bolivia C. CHILE (2018) párrafo 25.

Respecto al Tratado de 1904 ver Bustos (2004) pp. 109-26; Pinochet de la Barra (2004) pp. 29-35; Figueroa (2007) pp. 30-3; Lira (2009) pp. 159-69; Lagos Erazo (2014) pp. 96-102; y Bustos (2018) pp. 251-72. Ver en general Concha y Garay (2013); y MAYER (2018).

Sobre la fijación de la frontera entre Bolivia y Chile ver BenAdava (1993) pp. 25-32; Bustos (2004) pp. 86-94 \& 109-26; Figueroa (2007) pp. 21-33; Lira (2009) pp. 146-69; y Bustos (2018) pp. 187-91 \& 251-72.

26 Ver Bolivia C. CHILE (2018) párrafos 16-83 \& 91-174.

27 Ver Bolivia C. Chile (2018) párrafo 89. Ver también Bolivia C. Chile (2015) párrafo 34.

28 Ver Bolivia C. Chile (2018) párrafo 88. Ver también Bolivia C. ChILE (2015) párrafos 33 \& 35.

29 Ver Bolivia C. ChILe (2018) párrafo 90.
} 
con Bolivia, la Corte hizo algunas precisiones teóricas sobre el objeto de la controversia, que son claves para entender el resultado de este juicio. De acuerdo al tribunal, los estados son libres de empezar a negociar o de dejar de hacerlo, lo que no obsta a que puedan acordar contraer un deber en este sentido ${ }^{30}$. Con citas a los asuntos de la plataforma Continental del Mar del Norte y de la aplicación del acuerdo provisional de 13 de septiembre de 1995 (Macedonia c. Grecia), la Corte señaló al respecto que los estados tienen que comportarse de modo tal que las negociaciones sean significativas. Vale decir, evitando insistir porfiadamente en una posición que no acepte modificación, y dando una consideración razonable a los intereses ajenos ${ }^{31}$. El tribunal recurrió al asunto de las plantas de celulosa sobre el Río Uruguay para recordar que, si bien las conversaciones entre estados pueden llevar a que acuerden algo que resuelva una controversia, la obligación de negociar no implica un deber de alcanzar un acuerdo, lo cual solo se puede exigir cuando se haya contraído una "obligación de lograr un resultado preciso", del tipo que puede observarse en el Artículo VI del Tratado sobre la No Proliferación de las Armas Nucleares, calificada en la opinión consultiva sobre legalidad de la amenaza o del uso de armas nucleares como un deber que va más a allá de una mera obligación de conducta ${ }^{32}$.

De acuerdo al tribunal, el hecho de que haya negociaciones interestatales sobre un determinado asunto, no hace obligatorias estas para las partes. Como en toda otra obligación jurídica, para determinar la existencia de un deber de negociar de naturaleza contractual se debe atender a la intención de las partes, manifestada en los términos empleados en el acuerdo respectivo, así como en el objeto y las condiciones de las negociaciones acordadas. Ausente lo anterior, esta intención "puede ser establecida sobre la base de un examen objetivo de toda la evidencia ${ }^{33}$. Dado que a lo largo del juicio Bolivia sostuvo que la obligación de negociar que tendría Chile proviene principalmente de supuestos acuerdos bilaterales, el tribunal comenzó su análisis por estos ${ }^{34}$. $\mathrm{Al}$ respecto, la sentencia indicó que el Artículo 3 de la Convención de Viena sobre el Derecho de los Tratados, que refleja el derecho internacional en la materia, acepta que los acuerdos no celebrados por escrito también pueden tener validez jurídica, en la medida que las partes hayan manifestado su intención en obligarse. Esto incluiría a los acuerdos tácitos, de tanta importancia en la disputa marítima (Perú c. Chile); en cuyo caso, tal como lo había señalado en la disputa marítima y territorial (Nicaragua c. Honduras), su prueba requiere ser convincente ${ }^{35}$. El estudio de estos supuestos acuerdos bilaterales entre Bolivia y Chile partió con la así llamada acta pro-

\footnotetext{
30 Ver Bolivia C. CHILE (2018) párrafo 86.

31 Ver Bolivia C. Chile (2018) párrafo 86. Ver también Alemania C. Dinamarca, y Alemania C. PaÍses Bajos (1969) párrafo 85; y MACEDONIA C. GRECIA (2011) párrafo 132.

32 Bolivia C. Chile (2018) párrafo 87. Ver ARgENTINA C. URUGUAY (2010) párrafo 150. Al respecto, el tribunal hizo referencia, asimismo, al asunto del tRAFICO FERROVIARIO ENTRE LITUANIA Y POLONIA (1931) p. 116. Ver también LEGALIDAD DE LA AMENAZA O DEL USO DE ARMAS NUCLEARES (1996) párrafo 99.

33 Ver Bolivia C. Chile (2018) párrafo 91.

34 Ver Bolivia C. Chile (2018) párrafos 92-3.

35 Ver Bolivia C. CHILe (2018) párrafo 97.

Ver también Nicaragua C. Colombia (2007) párrafo 253; y Perú C. ChILE (2014) párrafo 91.

Cabe señalar que la Corte hizo mención solo al primero de estos casos en su sentencia en el asunto de la obligación de negociar un acceso al Océano Pacífico.
} 
tocolizada de 1920. Como da cuenta el tribunal, Bolivia cambió rápidamente de opinión después de haber celebrado el Tratado de Paz y Amistad con Chile. Ya en 1910, declaró en un memorándum que su mediterraneidad la compromete existencialmente, por lo que no puede mantenerse inactiva frente las negociaciones chileno-peruanas sobre Tacna y Arica ${ }^{36}$. Nueve años más tarde, Chile manifestó oficialmente estar dispuesto a negociar con Bolivia una salida al mar, sujeta al resultado del plebiscito contemplado en el Tratado de Ancón de 1883, e "independientemente de lo estipulado por el Tratado de Paz de 1904" 37 . Unos pocos meses después, Bolivia y Chile se reunieron para tratar diversos asuntos, incluyendo el del acceso al mar, de lo cual quedó registro en un documento escrito que pasó a conocerse como "acta protocolizada" ${ }^{38}$. Conforme a este, Chile propuso otorgar a Bolivia una salida propia al mar al norte de Arica y de la línea del ferrocarril, "dentro de los territorios sometidos al plebiscito estipulado en el Tratado de Ancón”, en la medida que Chile triunfe en este y se quede con las provincias en disputa con Perú, y que Bolivia le compense dicha cesión. ${ }^{39}$ Los términos propuestos por Chile fueron aceptados por Bolivia, quien agregó explícitamente que "las presentes declaraciones no contienen estipulaciones que generen derechos ni obligaciones para los Estados [que] las formulan" 40 .

Citando a la delimitación marítima y cuestiones territoriales (Qatar c. Bahrein), el tribunal recordó que las actas firmadas de una reunión pueden constituir un acuerdo si ellas enumeran los compromisos a los que han consentido los estados, y no se restringen simplemente a dar cuenta de lo discutido o a resumirlo ${ }^{41}$. En opinión de la Corte, el acta protocolizada tuvo un valor político, pero no revela que Chile haya aceptado una obligación de negociar un acceso soberano al Océano Pacífico para Bolivia ${ }^{42}$. Esto, por cuanto no enumeró compromiso alguno; de hecho, ni siquiera resumió los puntos de acuerdo y desacuerdo. Por si fuera poco, el acta protocolizada de 1920 dejó además constancia expresa de que Bolivia consideraba que esta no contenía estipulaciones que generen derechos ni obligaciones, lo cual no fue controvertido por Chile ${ }^{43}$.

\section{INTERCAMBIOS DIPLOMÁTICOS HASTA LOS 60}

Con posterioridad al acta protocolizada, la sentencia se refirió a la solicitud de revisión del Tratado de 1904 que Bolivia realizó a la Sociedad de las Naciones, la cual fue declarada inadmisible por una comisión ad hoc de juristas ${ }^{44}$. Chile manifestó entonces, y

\footnotetext{
36 Bolivia C. Chile (2018) párrafo 26.

37 Bolivia C. Chile (2018) párrafo 27.

38 Ver Bolivia C. CHILE (2018) párrafo 28

39 Bolivia C. ChILe (2018) párrafo 29.

40 Bolivia c. Chile (2018) párrafo 31. Ver Bolivia C. Chile (2018) párrafo 30.

En cuanto el acta protocolizada de 1920 ver Bustos (2004) pp. 137-9; Pinochet DE LA BARRA (2004) pp. 37-41; Lagos Erazo (2014) pp. 130-1; Lagos Erazo (2016) p. 190; y Bustos (2018) pp. 307-10. Ver también FigueROA (2007) pp. 35-40.

41 Ver Bolivia C. ChILE (2018) párrafo 106. Ver QATAR C. BAHREIN (1994) párrafo 25.

42 Ver Bolivia C. CHILE (2018) párrafo 105. Ver también Bolivia C. CHILE (2018) párrafo 107.

43 Ver Bolivia C. CHILE (2018) párrafo 106.

44 Ver Bolivia C. CHILE (2018) párrafos 32-3.
} 
reiteró en diversas oportunidades después, estar dispuesto a sentarse a conversar sobre las aspiraciones portuarias de Bolivia, sin modificar dicho tratado ni interrumpir la continuidad de su territorio ${ }^{45}$. En un laudo arbitral de 1925, el presidente de EE.UU., Calvin Coolidge (1872-1933), estableció los términos y condiciones del plebiscito sobre Tacna y Arica contemplado en el Artículo 3 del Tratado de Ancón ${ }^{46}$. Un año después, el secretario de estado de ese país, Frank Kellogg (1856-1937), propuso a Chile y Perú que cedan a perpetuidad dichas provincias a Bolivia, quien tendría que compensarles de una forma a determinar ${ }^{47}$. Bolivia aceptó plenamente la propuesta Kellogg, mientras que Chile a través de un memorándum de su ministro de relaciones exteriores, Jorge Matte (1876-1944), dirigido al secretario de estado de EE.UU., expresó que aun cuando Chile ha manifestado en repetidas veces su deseo de satisfacer las aspiraciones bolivianas a través de una franja de territorio y un puerto, la solución propuesta va más allá y depende del resultado de un plebiscito $^{48}$. Perú, por su parte, informó a EE.UU. que no aceptada la propuesta Kellogg ${ }^{49}$. Al no estar dirigido a Bolivia, ni contener algo en su redacción que pudiera indicar que Chile contrajo o reconoció una obligación de negociar, el memorándum Matte constituyó para la Corte "un paso político significativo", pero nada más ${ }^{50}$. El plebiscito contemplado en el laudo de 1925 no pudo llevarse a cabo en los años siguientes debido a dificultades que surgieron en su implementación, por lo que Chile y Perú decidieron solucionar el problema de la soberanía de Tacna y Arica por medio de un nuevo tratado ${ }^{51}$. Celebrado en 1929, bajo el nombre de Tratado de Lima, en virtud de este la soberanía de Tacna quedó para Perú y la de Arica para Chile. Ese mismo año, en un protocolo complementario a este acuerdo internacional, Chile y Perú se comprometieron a no ceder a un tercer estado, sin previo acuerdo entre ellos, la totalidad o parte de los territorios que quedaron bajo su soberanía conforme al Tratado de Lima ${ }^{52}$. Tras recibir estos acuerdos internacionales en 1929, Bolivia reaccionó

\footnotetext{
45 Ver Bolivia C. CHILe (2018) párrafos 34-40.

Respecto al reclamo boliviano ante la Sociedad de las Naciones ver Bustos (2004) pp. 141-6; Figueroa (2007) pp. 43-58; Lira (2009) pp. 224-30; Lagos Erazo (2013) pp. 21-2; Lagos Erazo (2016) pp. 61-2; y Bustos (2018) pp. 299-306.

Sobre las negociaciones entre Bolivia y Chile en este período, hasta 1925, ver PinOCHET DE LA BARRA (2004) pp. 41-2; Figueroa (2007) pp. 35-41, 43-57 \& 59-64; Lagos Erazo (2014) p. 130; y Lagos Erazo (2016) pp. $190-1$.

46 Ver Bolivia C. CHILe (2018) párrafo 41.

47 Ver Bolivia C. CHILe (2018) párrafo 42.

48 Ver Bolivia C. Chile (2018) párrafo 44. Ver Bolivia C. CHILe (2018) párrafo 43.

49 Ver Bolivia C. CHILE (2018) párrafo 45.

En cuanto a la propuesta Kellogg de 1926 y el memorándum Matte de ese año ver Bustos (2004) pp. 151-3; Pinochet de la Barra (2004) pp. 42-7; Figueroa (2007) pp. 65-8; Lagos Erazo (2014) pp. 131-2; Lagos Erazo (2016) pp. 191-2; y Bustos (2018) pp. 325-7.

50 Bolivia C. CHILE (2018) párrafo 107.

51 Ver Bolivia C. CHILE (2018) párrafo 47.

52 Ver Bolivia C. Chile (2018) párrafo 48.
} 
enviando un memorándum al secretario de estado de EE.UU., donde afirmó que no por eso iba a renunciar a su política de reintegración marítima soberana ${ }^{53}$.

Hacia finales de la década de los 40, las partes en litigio volvieron a conversar sobre este tema. En 1950, Bolivia envió a su vecino del suroeste una propuesta formal de negociar un acceso con soberanía al mar ${ }^{54}$. Chile respondió ese mismo año que, sin perjuicio de lo establecido en el Tratado de 1904, estaba dispuesto a comenzar una negociación para buscar una posible salida soberana al Océano Pacífico, la cual debía ser compensada por Bolivia ${ }^{55}$. Esta negociación no tuvo lugar, pero en 1951 el presidente de Chile, Gabriel González Videla (1898-1980), indicó que escuchar las proposiciones de Bolivia para dar solución a su mediterraneidad ha sido la política invariable de su estado, siempre que estas se hagan directamente a Chile "y sin que ello hubiera significar un abandono de nuestra doctrina respecto a los tratados internacionales, que estimamos esencial para la convivencia pacífica entre las naciones" ${ }^{56}$. Agregó en esa oportunidad González Videla que, en todo momento en que Bolivia ha manifestado su deseo de conversar sobre este tema, se han planteado las dos condiciones que deben acompañar a cualquier solución: ofrecer una compensación para Chile y contar con el acuerdo de Perú ${ }^{57}$. En su análisis del intercambio de 1950, la Corte aludió al Artículo 2.1 de la Convención de Viena de 1969, que señala que un tratado puede constar en dos o más instrumentos conexos, y al Artículo 13 de dicho acuerdo internacional, que indica que la manifestación del consentimiento de los estados en obligarse por un tratado mediante el canje de instrumentos requiere que estos dispongan que el intercambio tendrá ese efecto o bien que conste de otro modo que esos estados han convenido en eso $^{58}$. Según el tribunal, ninguna de estas condiciones puede considerarse cumplida en este caso, debido a que las notas no dijeron nada sobre su efecto, por un lado, y Bolivia no presentó prueba suficiente de un acuerdo alternativo, por otro ${ }^{59}$. Asimismo, la Corte señaló que el intercambio de notas de 1950 no siguió la práctica usual de celebración de un acuerdo internacional por medio de canje de instrumentos conexos, consistente en el intercambio de documentos de contenido idéntico en los que cada estado expresa su oferta y su aceptación, respectivamente ${ }^{60}$. Según el tribunal, lo más que se puede inferir de este episodio es la intención de Chile de iniciar conversaciones con Bolivia ${ }^{61}$. Como indica en su sentencia, entre 1951 y 1957 las partes litigantes centraron sus esfuerzos en mejorar

\footnotetext{
53 Ver Bolivia C. CHILE (2018) párrafo 49.

Respecto a la reacción de Bolivia al Tratado de Lima de 1929 y su protocolo complementario ver Bustos (2004) pp. 155-8; y Bustos (2018) pp. 329-40.

54 Ver Bolivia C. CHILE (2018) párrafo 51.

55 Ver Bolivia C. Chile (2018) párrafo 52.

56 Bolivia C. Chile (2018) párrafo 53.

57 Ver Bolivia C. ChILe (2018) párrafo 53.

Sobre el intercambio de notas de 1950 ver Bustos (2004) pp. 161-80; Pinochet de la Barra (2004) pp. 5561; Figueroa (2007) pp. 73-82; Lira (2009) pp. 313-20; Lagos Erazo (2014) pp. 132-4; Lagos Erazo (2016) pp. 192-3; у Bustos (2018) pp. 367-78.

58 Ver Bolivia C. CHILE (2018) párrafo 116.

59 Ver Bolivia C. CHILE (2018) párrafo 116.

60 Ver Bolivia C. CHILE (2018) párrafo 117.

${ }^{61}$ Ver Bolivia C. Chile (2018) párrafo 118.
} 
la implementación de la salida al mar que tiene Bolivia conforme al Tratado de $1904^{62}$. Algunos años después, el embajador de Chile en Bolivia, Manuel Trucco (1914-1995), decidió entregar un memorándum al ministro de relaciones exteriores boliviano, que ya había enviado al ministro de relaciones exteriores chileno. A fin de evitar que Bolivia plantee el tema de su mediterraneidad en la conferencia interamericana que iba a realizarse en Quito, Ecuador, el así llamado "memorándum Trucco" de 1961 declaró que Chile siempre ha estado abierto a satisfacer las aspiraciones de Bolivia, en la medida que no se altere la situación establecida en el Tratado de 1904 y se negocie bilateralmente ${ }^{63}$. La respuesta de Bolivia vino en 1962, a través de un memorándum de su ministro de relaciones exteriores que declaró el interés de su estado de iniciar negociaciones con Chile para alcanzar una salida soberana al Océano Pacífico ${ }^{64}$. Ese mismo año, no obstante, Bolivia cortó relaciones diplomáticas con Chile por el uso que este le daba a las aguas del Río Lauca ${ }^{65}$. En 1963, Chile negó expresamente que el memorándum Trucco haya constituido una nota oficial, ya que no pasó de ser un simple aide memoire donde se expusieron ciertos puntos de vista, en un momento determinado ${ }^{66}$. Al respecto, la Corte observó que este documento además no haber sido formalmente dirigido a Bolivia, y solo entregado a sus autoridades, únicamente reitera ciertas declaraciones hechas en la nota chilena de 1950, sin crear ni reafirmar una obligación de negociar un acceso boliviano al mar con soberanía ${ }^{67}$.

\section{NEGOCIACIONES FRUSTRADAS A PARTIR DE LOS 70}

En un comunicado conjunto de 1974, los presidentes de Bolivia y Chile, generales Hugo Banzer (1926-2002) y Augusto Pinochet (1915-2006), respectivamente, expresaron estar de acuerdo en iniciar negociaciones sobre "asuntos pendientes y fundamentales" 68. Junto a otros estados de América Latina, las partes en litigio firmaron la Declaración de Ayacucho, en la cual manifestaron su disposición a prestar la más amplia consideración a la mediterraneidad que afecta a Bolivia ${ }^{69}$. En 1975, los presidentes de ambos estados firmaron la Declaración de Charaña, donde reafirmaron su plena adhesión a lo acordado en Perú un año antes, y acordaron continuar el diálogo para buscar fórmulas de solución que sean recíprocamente convenientes ${ }^{70}$. Después de este encuentro, Bolivia propuso unas pautas de negociación, a las cuales Chile respondió con una contrapropuesta condicionada a un intercambio territorial entre ambos estados, que no innove respecto de lo estipulado en el

\footnotetext{
${ }^{62}$ Ver Bolivia C. ChILE (2018) párrafo 54.

${ }^{63}$ Bolivia C. CHILE (2018) párrafo 55.

${ }^{64}$ Ver Bolivia C. CHILe (2018) párrafo 56.

En cuanto al memorándum Trucco ver Figueroa (2007) pp. 83; Lira (2009) pp. 320-1; Lagos Erazo (2014) pp. 134-5; y Lagos Erazo (2016) pp. 194-5. Ver también Pinochet de la Barra (2004) pp. 63-9.

65 Ver Bolivia C. CHILe (2018) párrafo 57.

66 Ver Bolivia C. Chile (2018) párrafo 58. Ver Bolivia C. ChILe (2018) párrafo 59.

67 Ver Bolivia C. CHILE (2018) párrafo 119.

68 Bolivia C. CHILE (2018) párrafo 60.

69 Ver Bolivia C. CHILE (2018) párrafo 61.

70 Ver Bolivia C. Chile (2018) párrafo 62. Ver también Bolivia C. ChILE (2018) párrafo 63.
} 
Tratado de 1904. En esa oportunidad, Chile manifestó estar dispuesto a negociar la cesión de una franja de territorio que iba desde el norte de Arica hasta la frontera con Perú, y de ahí hasta Bolivia, descartando de plano incluir en estas conversaciones áreas al sur de dicha faja de tierra, pues afectaría la continuidad territorial del país. Chile, además, supeditó la validez de esta solución al acuerdo previo de Perú, conforme al protocolo complementario del Tratado de $\operatorname{Lima}^{71}$. Bolivia aceptó la contrapropuesta chilena como una base para negociar, pero en 1976 agregó que su aceptación del intercambio territorial allí mencionado dependía de que se aclare el área marítima incluida, reservándose la posibilidad de negociar las zonas que podrían ser objeto de un eventual canje ${ }^{72}$. Las partes litigantes establecieron una comisión mixta permanente, y a lo largo de ese año Bolivia confirmó su disposición a considerar un intercambio territorial con Chile $^{73}$. En cumplimiento de lo señalado en el protocolo complementario del Tratado de Lima, Chile le preguntó a Perú en 1975 si estaba de acuerdo con la cesión territorial antes mencionada, y Perú respondió en 1976 con su propia contrapropuesta, en la cual planteaba la posibilidad de crear una zona bajo soberanía tripartita en la parte que la franja territorial daba al mar, lo que no fue aceptado por Chile ni por Bolivia ${ }^{74}$. Ese mismo año, el general Banzer anunció públicamente que le había propuesto a Chile que elimine la condición de canje territorial. Pese a esto, durante 1977 las negociaciones entre Bolivia y Chile continuaron en base a los intercambios de 1975. Los ministros de relaciones exteriores de ambos estados incluso emitieron una nueva declaración conjunta en la que destacaron su empeño en dialogar para buscar soluciones concretas a la mediterraneidad boliviana ${ }^{75}$. Hacia fines de ese año, sin embargo, el presidente de Bolivia insistió en que la condición chilena de intercambio territorial debía ser retirada, esta vez junto con la contrapropuesta peruana de una zona de soberanía compartida entre los tres estados ${ }^{76}$. En 1978, Chile reiteró que las bases de negociación eran las acordadas en 1975, y Bolivia respondió que suspendía las relaciones diplomáticas entre ambos estados "debido a la falta de flexibilidad de Chile respecto de las condiciones de las negociaciones y la falta de esfuerzo por parte de Chile para obtener el consentimiento del Perú para el intercambio de territorio"77. Con esto terminó el proceso de Charaña ${ }^{78}$.

En su análisis de este conjunto de intercambios diplomáticos, el más importante que tuviera lugar entre Bolivia y Chile después del Tratado de 1904, la Corte se centró en la Declaración de Charaña de 1975, respecto de la cual señaló que "es un documento que fue firmado por los Presidentes de Bolivia y Chile, que podría ser caracterizado como un tra-

\footnotetext{
71 Ver Bolivia C. ChILE (2018) párrafo 64.

72 Ver Bolivia C. Chile (2018) párrafo 65.

73 Ver Bolivia C. Chile (2018) párrafo 66.

74 Ver Bolivia C. ChILE (2018) párrafo 67.

75 Ver Bolivia C. CHILE (2018) párrafo 68

76 Ver Bolivia C. CHILe (2018) párrafo 69.

77 Bolivia C. CHILE (2018) párrafo 70.

78 Sobre el proceso de Charaña ver Bustos (2004) pp. 221-37; Pinochet de la Barra (2004) pp. 75-87; MiLLAR (2005) pp. 419-23; Figueroa (2007) pp. 117-37; Lira (2009) pp. 322-69; Rodríguez Elizondo (2009); pp. 21-30; Lagos Erazo (2010) pp. 33-7; Tapia y Mardones (2011) pp. 37-64; Infante (2014) pp. 34-64; Lagos Erazo (2014) pp. 135-7; Lagos Erazo (2016) pp. 195-7; y Bustos (2018) pp. 469-87.
} 
tado si las Partes hubieran expresado una intención de verse obligadas por ese instrumento o si tal intención pudiera ser inferida de otra manera"79. Según el tribunal, el lenguaje de esta declaración indica que es un documento de carácter político que enfatiza la atmósfera de cordialidad y fraternidad, así como el espíritu solidario, que llevó a los dos estados a normalizar sus relaciones diplomáticas. Esta redacción no permite concluir que Chile haya contraído o confirmado una obligación de negociar con Bolivia, más aún relativa a un supuesto acceso soberano al Océano Pacífico que ni siquiera es mencionado explícitamente en la Declaración de Charaña ${ }^{80}$. Sin perjuicio de esta conclusión, la sentencia reconoció que las partes en litigio sostuvieron con posterioridad negociaciones significativas que involucraron una contrapropuesta chilena de cesión territorial concreta, condicionada a un intercambio de territorio equivalente, y una contrapropuesta peruana de establecimiento de una zona de soberanía conjunta, en el litoral de la franja puesta a su consideración, lo que tanto Bolivia como Chile rechazaron, llevando las negociaciones a su fin ${ }^{81}$. Las partes litigantes volvieron a conversar sobre este asunto solo en 1986, y así se lo informaron en dos comunicados conjuntos a la Asamblea General de la OEA, que tomó nota de esto en su resolución AG/RES. 816 $6^{82}$. El llamado a reanudar el diálogo vino del presidente de Bolivia, Víctor Paz Estenssoro (1907-2001), quien propuso a Chile negociar con un enfoque nuevo, que es el nombre que después recibieron estos intercambios diplomáticos. En 1987, los ministros de relaciones exteriores boliviano y chileno se reunieron en Montevideo, Uruguay. Ahí, Bolivia presentó dos propuestas alternativas a Chile para acceder al Océano Pacífico, mediante transferencias territoriales soberanas ${ }^{83}$. Chile rechazó ambas propuestas, por lo que Bolivia anunció en la Asamblea General de la OEA la suspensión de las negociaciones bilaterales, lo cual fue registrado por dicho órgano ${ }^{84}$. En su estudio de estos intercambios diplomáticos, la Corte recordó algo que había señalado en plataforma continental del Mar Egeo: que no existe una norma de derecho internacional que impida a un comunicado conjunto constituir un tratado, lo que va a depender "esencialmente de la

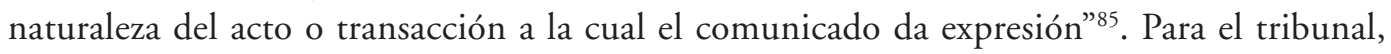
las declaraciones que hicieran Bolivia y Chile en 1986 son instrumentos separados, cuya redacción es diferente y que no hacen referencia a una salida soberana al mar. Esto, sumado a la conducta subsiguiente observada por las partes en litigio, llevó a la Corte a concluir que

\footnotetext{
79 Bolivia C. Chile (2018) párrafo 126.

80 Ver Bolivia C. CHILE (2018) párrafo 126.

81 Ver Bolivia C. CHILE (2018) párrafo 127.

82 Ver Bolivia C. ChILE (2018) párrafo 76. Las resoluciones de la Asamblea General de la OEA están disponibles en: <http://www.oas.org/es/sla/resoluciones_asamblea_general.asp> [fecha de consulta: 1 de abril de 2020]

83 Ver Bolivia C. CHILe (2018) párrafo 77.

${ }^{84}$ Ver Bolivia C. CHILe (2018) párrafo 77.

En cuanto al enfoque fresco ver Bustos (2004) pp. 258-75; Pinochet de LA Barra (2004) pp. 90-3; Figueroa (2007) pp. 243-50, 258-60 \& 262-79; TAPIA y MARdones (2011) pp. 65-113; Lagos Erazo (2014) pp. 137-43; y Lagos Erazo (2016) pp. 198-203.

85 Bolivia C. ChILE (2018) párrafo 131. Ver GRECIA C. TURQUía (1978) párrafo 96.
} 
Chile tampoco contrajo o aceptó en esa ocasión una obligación de negociar con Bolivia un acceso al Océano Pacífico ${ }^{86}$.

Las conversaciones entre Bolivia y Chile, sobre diversos asuntos de interés común, fueron reanudadas en 1995, tomando el nombre de mecanismo de consultas ${ }^{87}$. Cinco años después, los ministros de relaciones exteriores de ambos estados emitieron un nuevo comunicado conjunto, conocido como Declaración de Algarve, que contemplaba una agenda de trabajo de varios temas, sin exclusiones ${ }^{88}$. Entre 2000 y 2003, las partes en litigio vieron la posibilidad de que Chile otorgue una concesión a Bolivia para la creación de una zona económica especial por un período inicial de cincuenta años, proyecto que fue finalmente rechazado por los bolivianos ${ }^{89}$. Según la Corte, la Declaración de Algarve no constituyó un acuerdo que le imponga a Chile una obligación de negociar con Bolivia. Como explicó en su sentencia, este comunicado conjunto de 2000 no hizo referencia al asunto de una salida al mar, y solo muestra la voluntad de Bolivia y Chile de dialogar sin exclusión alguna sobre una agenda de trabajo a ser definida con el fin de establecer un ambiente de confianza entre ambas ${ }^{90}$. Después de la Declaración de Algarve, los intercambios diplomáticos entre las partes en litigio continuaron. En 2006, Bolivia y Chile anunciaron públicamente una Agenda de los 13 Puntos, destinada a abarcar todos los temas relevantes de su relación bilateral, incluyendo expresamente el marítimo ${ }^{91}$. Las reuniones del mecanismo de consulta que siguieron se ocuparon de este asunto. Entre 2009 y 2010 se discutió la creación de un enclave boliviano en la costa chilena, estableciéndose incluso una comisión binacional al efecto ${ }^{92}$. En 2011, el presidente de Bolivia, Evo Morales, solicitó a Chile una propuesta concreta que sirva de base para el debate ${ }^{93}$. La respuesta del presidente de Chile, Sebastián Piñera, consistió en reiterar la propuesta del enclave sin soberanía, condicionándola esta vez no solo al cumplimiento del Tratado de 1904, sino también a la modificación del artículo de la Constitución Política boliviana que hace mención a su salida al mar ${ }^{94}$. A juicio de la Corte, la mera mención del tema marítimo en la Agenda de los 13 Puntos no permite concluir que Chile haya contraído o reconocido una obligación de negociar con Bolivia ${ }^{95}$.

\section{SUPUESTOS ACTOS UNILATERALES, ESTOPPEL Y AQUIESCENCIA}

En sus escritos y alegatos, Bolivia señaló que la obligación de negociar un acceso soberano también se funda en diversos actos unilaterales de Chile, así como en comportamientos recíprocos del estado. Citando los asuntos de los ensayos nucleares (Australia c.

\footnotetext{
${ }^{86}$ Ver Bolivia C. CHILE (2018) párrafo 132.

87 Ver Bolivia C. CHILE (2018) párrafo 78.

88 Ver Bolivia C. Chile (2018) párrafo 78.

89 Ver Bolivia C. CHILE (2018) párrafo 79.

90 Ver Bolivia C. Chile (2018) párrafo 135.

91 Ver Bolivia C. Chile (2018) párrafo 80.

92 Ver Bolivia C. CHILE (2018) párrafos 81-2.

93 Ver Bolivia C. CHILE (2018) párrafo 83.

94 Ver Bolivia C. Chile (2018) párrafo 83.

95 Ver Bolivia C. ChILE (2018) párrafo 138.
} 
Francia) y (Nueva Zelanda c. Francia), la Corte reiteró que, para obligar jurídicamente a un estado, una declaración requiere ser: pública, precisa e intencionada, y seguida de una conducta estatal consistente ${ }^{96}$. De acuerdo a lo resuelto en actividades armadas en el territorio del Congo, los efectos jurídicos de una declaración hecha por un representante del estado dependen de su contenido y de las circunstancias en las que se hizo ${ }^{97}$. Teniendo en cuenta estas consideraciones, la Corte observó que la redacción de las declaraciones de Chile, y el contexto en las que se dieron, no denotan una intención de contraer una obligación jurídica, sino simplemente la de entrar a negociar sobre el asunto de la mediterraneidad de Bolivia $^{98}$. En cuanto a la aquiescencia, el tribunal se remitió a dos frases de las sentencias recaídas en los asuntos de la delimitación de la frontera marítima en el Golfo de Maine y de la soberanía sobre Pedra Branca/Pulau Batu Puteh, Middle Rocks y South Ledge. Estas señalan, respectivamente, que "la aquiescencia equivale a un reconocimiento tácito manifestado por una conducta unilateral que la otra parte puede interpretar como consentimiento", y que "el silencio también puede hablar, pero solo si la conducta del otro Estado pide una respuesta" 99 . Según el tribunal, Bolivia no identificó ninguna declaración que requiera una respuesta o reacción por parte de Chile, a fin de prevenir el surgimiento una obligación, por lo que la aquiescencia no se presenta en este caso ${ }^{100}$. Como con los actos unilaterales y la aquiescencia, la sentencia tampoco se extendió mayormente respecto del estoppel. La Corte recurrió al asunto de la disputa territorial, insular y marítima (El Salvador/Honduras) para recordar que los elementos esenciales de este son: una declaración hecha por una de las partes a otra, por un lado; y la confianza puesta por esta en dicha declaración, en su detrimento o en favor del declarante, por otra ${ }^{101}$. Para ejemplificar cómo opera el estoppel en una situación similar a la del caso de Bolivia con Chile, el tribunal aludió al asunto de la disputa territorial y marítima (Camerún c. Nigeria). En este caso, la Corte señaló que un estoppel requeriría no solo que un estado haya expresado a través de actos y declaraciones, de manera clara y consiste, haber acordado solucionar una controversia exclusivamente por vías bilaterales, sino además que otro estado haya cambiado de posición, en su propio detrimento o sufriendo algún perjuicio ${ }^{102}$. Aplicando estas consideraciones al asunto de la obligación de negociar un acceso al Océano Pacífico, el tribunal resolvió que las condiciones esenciales de un estoppel no se han reunido, por dos motivos: primero, porque Chile ha manifestado repetidamente su disposición a negociar una salida soberana al mar para Bolivia, sin que esto indique que se haya obligado a eso; y, segundo, porque Bolivia no

\footnotetext{
96 Ver Bolivia C. ChILE (2018) párrafo 146. Ver también Australia C. FRANCIA (1974) párrafo 43; y NUEVA ZELANDA C. FRANCIA (1974) párrafo 46.

97 Ver Bolivia C. ChILE (2018) párrafo 146. Ver también CONGO C. RUANDA (2006) párrafo 49.

98 Ver Bolivia C. CHILE (2018) párrafos 147-8.

99 Bolivia C. ChILE (2018) párrafo 152. Ver CANADA/EE.UU. (1984) párrafo 130; y MaLASIA/SINGAPUR (2008) párrafo 121.

100 Ver Bolivia C. CHILE (2018) párrafo 152.

101 Ver Bolivia C. ChILE (2018) párrafo 158. Ver también EL SALVADOR/Honduras (1990) párrafo 63.

102 Ver Bolivia C. ChILe (2018) párrafo 158. Ver también CAMERÚN C. NiGERIA (1998) párrafo 57.
} 
pudo demostrar que a raíz de las declaraciones de Chile cambió de posición en su propio detrimento o para ventaja de este ${ }^{103}$.

Junto a los actos unilaterales, la aquiescencia y el estoppel, Bolivia recurrió a otras figuras que también fueron desestimadas por la Corte. Una de estas fue la del respeto de las expectativas legítimas, supuestamente creadas a su favor por las múltiples declaraciones efectuadas por Chile de otorgar una salida soberana al mar, a lo largo de los años. La Corte no estuvo de acuerdo con esto, pues no existe en el derecho internacional general un principio que permita crear una obligación jurídica a partir de una expectativa legítima ${ }^{104}$. Para el tribunal, las referencias a esta figura se pueden encontrar en la jurisprudencia de arbitrajes de diferencias inversionista-estado, particularmente en lo relativo a la cláusula del trato justo y equitativo ${ }^{105}$. Otra afirmación que hizo Bolivia, y que fue desestimada por la Corte, es que los Artículos 2.3 de la Carta de la ONU y 3.i de la Carta de la OEA establecen una obligación general de negociar en el derecho internacional, aplicable a cualquier asunto pendiente que involucre a dos más estados, cuando dicen que "[l]os Miembros de la Organización [de las Naciones Unidas] arreglarán sus controversias internacionales por medios pacíficos de tal manera que no se pongan en peligro ni la paz y la seguridad internacionales ni la justicia", y que "[l] as controversias de carácter internacional que surjan entre dos o más Estados americanos deben ser resueltas por medio de procedimientos pacíficos", respectivamente. Sobre esta aseveración boliviana, la Corte indicó que el Artículo 2.3 de la Carta de la ONU establece un deber general de solución pacífica de las controversias internacionales, y que esta disposición no contempla una obligación para las partes en litigio de recurrir a un método específico, como la negociación. Esto se condice con lo prescrito en el Artículo 33 del mismo tratado, que deja a las partes la elección del método concreto para solucionar una disputa internacional ${ }^{106}$. De acuerdo al tribunal, el Artículo 3.i de la Carta de la OEA correctamente interpretado a la luz de lo dispuesto en los Artículos 25 y 25 de este tratado, consagra un deber general de solución pacífica de controversias internacionales similar al de la Carta de la ONU. Vale decir, uno que no exige recurrir a un mecanismo específico, como la negociación ${ }^{107}$. Sobre la base de estas consideraciones, la Corte resolvió que no es posible extraer de las mencionadas disposiciones de las Cartas de la ONU y de

\footnotetext{
103 Ver Bolivia C. CHILE (2018) párrafo 159.

104 Ver Bolivia C. CHILE (2018) párrafo 162.

105 Ver Bolivia C. CHILE (2018) párrafo 162.

Lo cierto es que las expectativas legítimas no solo se han desarrollado respecto de esta protección de los tratados de inversión, sino también en el derecho internacional de la expropiación.

Ver en general López ESCARCENA (2014).

106 Ver Bolivia C. CHILE (2018) párrafo 165.

Como explicó la Corte, una postura similar adoptó la Asamblea General de la ONU en sus resoluciones 2625 (XXV) y $37 / 10$.

Ver Bolivia C. CHILE (2018) párrafo 166.

Las resoluciones de la Asamblea General de la ONU están disponibles en: <https://www.un.org/en/sections/ documents/general-assembly-resolutions/index.html> [fecha de consulta: 1 de abril de 2020]

107 Ver Bolivia C. CHILE (2018) párrafo 167.
} 
la OEA una obligación para Chile de negociar con Bolivia un acceso soberano al Océano Pacífico $^{108}$.

Bolivia asimismo adujo que en once resoluciones de la Asamblea General de la OEA se abordó el asunto de su salida al mar, las cuales confirmarían que Chile tiene una obligación de negociar incumplida. El contexto en el que estas se dieron es el siguiente. En paralelo al proceso de Charaña, y aprovechando el progresivo aislamiento internacional de Chile durante la dictadura de Augusto Pinochet, Bolivia llevó el asunto de su mediterraneidad a la OEA. En 1975, su Consejo Permanente adoptó por consenso la resolución CP/RES. 157 que declaró a este problema "motivo de preocupación continental" ${ }^{109}$. Entre 1979 y 1989, se sucedieron las mencionadas resoluciones de la Asamblea General de la OEA, las cuales reafirmaron la importancia del dialogo para encontrar una solución al asunto de la mediterraneidad boliviana. Aun cuando Chile no votó a favor de ninguna de estas resoluciones, tampoco se opuso al consenso en tres oportunidades, en las cuales hizo declaraciones y aclaraciones relativas a su contenido y naturaleza jurídica ${ }^{110}$. De particular relevancia fue la resolución AG/RES. 426 de 1979, donde la Asamblea General de la OEA indicó que era "de interés hemisférico encontrar una solución equitativa por la cual Bolivia obtenga acceso soberano y útil al Océano Pacífico" ${ }^{111}$. En esa ocasión, el representante de Chile protestó contra el proyecto de resolución, impugnó la competencia de la Asamblea General de esta organización internacional en el asunto, y declaró que Chile ha manifestado en reiteradas oportunidades su disposición a negociar con Bolivia una solución a su aspiración marítima soberana, pero que la única vía para alcanzar ese objetivo es la negociación bilateral, sin la injerencia de nadie más en estas conversaciones ${ }^{112}$. Conforme a la sentencia, ninguna de las resoluciones de la Asamblea General de la OEA invocadas por Bolivia sugiere que Chile tiene una obligación de negociar con esta. Por el contrario, estas solo recomiendan a las partes litigantes conversar sobre el asunto de la mediterraneidad boliviana. Difícilmente podrían haberlo hecho, pues las resoluciones de la Asamblea General de la OEA no son per se vinculantes, como lo reconocieron tanto Chile como Bolivia. Sobre este punto, agregó el tribunal que el silencio o inacción de Chile, necesarios para alcanzar el consenso requerido para aprobar algunas de las resoluciones de dicho órgano de la OEA, no implica que haya aceptado estar obligado jurídicamente por el contenido de estas ${ }^{113}$.

Por último, Bolivia señaló que aun cuando no haya un instrumento, acto o conducta que individualmente que permita concluir que Chile se obligó a negociar un acceso sobera-

108 Ver Bolivia C. CHILE (2018) párrafos 166-7.

109 Bolivia C. CHILE (2018) párrafo 71.

Las resoluciones del Consejo Permanente de la OEA están disponibles en: <http://www.oas.org/es/council/CP/ documentation/res_decs/> [fecha de consulta: 1 de abril de 2020]

110 Ver Bolivia C. CHILE (2018) párrafo 72.

111 Ver Bolivia C. CHILE (2018) párrafo 73.

112 Bolivia C. CHILE (2018) párrafo 73.

Respecto a las declaraciones de Bolivia y Chile ante la OEA, y resoluciones de esta, ver Bustos (2004) pp. 239-58; PinOCheT DE LA BARRA (2004) pp. 89-90; FigUeroa (2007) pp. 121-3, 147-73, 177-81, 182-5, 187-94, 206-15, 224-30, 236-41, 252-58, 281-4, 286-97, 305-15 \& 322-8; y Bustos (2018) pp. 505-18 \& 527-36.

113 Ver Bolivia C. Chile (2018) párrafo 171. 
no al Océano Pacífico para Bolivia, este deber puede colegirse de la consideración acumulativa de estos. Al respecto, la Corte simplemente resolvió que ningún efecto acumulativo puede provenir de instrumentos, actos o conductas que individualmente considerados no permiten concluir que Chile haya contraído dicha obligación ${ }^{114}$.

\section{FIN DE UNA ERA}

La sentencia del asunto de la obligación de negociar un acceso al Océano Pacífico fue adoptada por doce votos contra tres ${ }^{115}$. El presidente de la Corte, Abdulqawi Ahmed Yusuf, adjuntó una declaración en la que reiteró las consideraciones expresadas por esta sentencia sobre los requisitos necesarios para que surja una obligación de negociar, y recordó que la función del tribunal es resolver controversias internacionales por medio del derecho, lo cual no obsta a que las partes en litigio puedan buscar otras alternativas de solución, en caso de que la disputa entre estas subsista después del fallo ${ }^{116}$. Por su parte, cada uno de los tres jueces que votaron en contra de la sentencia acompañaron una opinión disidente a su voto. En la suya, el juez Patrick Robinson señaló haber concluido que Chile contrajo una obligación de negociar un acceso soberano al Océano Pacífico para Bolivia, por medio de ciertos acuerdos celebrados entre las partes litigantes. En concreto, los provenientes del memorándum Trucco de 1961 y la respuesta boliviana a este de 1962, y de las declaraciones conjuntas de Charaña de 1975 y $1977^{117}$. Por su parte, el juez Nawaf Salam consideró que los intercambios de notas de 1950 constituyeron un acuerdo bilateral en virtud del cual Chile se obligó a negociar con Bolivia una salida soberana al mar, tal como fue confirmado más tarde en el memorándum Trucco de 1961 y la respuesta que Bolivia dio a este en 1962, en la Declaración de Charaña de 1975, e incluso en la participación de Chile en las negociaciones del enfoque fresco y de la Agenda de los 13 Puntos de la década de 1990 y de 2000, respectivamente. El juez Salam calificó expresamente a esta obligación como de conducta $^{118}$. Finalmente, el juez ad hoc de Bolivia, Yves Daudet, también señaló que Chile contrajo una obligación de negociar un acceso soberano al Océano Pacífico para Bolivia sobre la base de acuerdos bilaterales alcanzados en el acta protocolizada de 1920, en el intercambio de notas diplomáticas de 1950 y en el proceso de Charaña de 1975-1978 ${ }^{119}$. A pesar de estas opiniones disidentes, la sentencia en el asunto de la obligación de negociar un acceso al Océano Pacífico solo puede ser calificada como categórica y contundente, no solo por el elevado número de jueces que votó a favor de lo resuelto en esta, sino también por su contenido. De hecho, lo fue a tal punto que ninguno de los representantes de las partes en litigio pudo disimular su asombro tras la lectura del fallo; en uno u otro sentido, obviamente. No pudo ser de otro modo, ya que después de rechazar cada uno de los argumentos presentados por el estado demandante, el tribunal declaró en un párrafo rotundo que, si

114 Ver Bolivia C. CHILE (2018) párrafo 174.

115 Ver Bolivia C. CHILE (2018) párrafo 177.

116 Ver en general BoLIVIA C. CHILE (2018, juez Yusuf).

117 Ver en general BolIVIA C. CHILE (2018, juez Robinson).

118 Ver en general Bolivia C. CHILE (2018, juez Salam).

119 Ver en general BolIVIA C. CHILE (2018, juez ad hoc Daudet). 
bien las partes litigantes "tienen una larga historia de diálogo, intercambios y negociaciones destinadas a identificar una solución apropiada a la situación de mediterraneidad de Bolivia posterior a la Guerra del Pacífico y al Tratado de Paz de 1904”, no es capaz de concluir de los antecedentes analizados que Chile tiene una obligación de negociar un acceso soberano al Océano Pacífico para esta ${ }^{120}$.

Desde la perspectiva del derecho internacional, esta sentencia no innovó mayormente en lo que se refiere a derecho de tratados, ni a derecho de actos unilaterales o de comportamientos recíprocos de los estados ${ }^{121}$. Ni siquiera lo hizo respecto de la obligación de negociar, como hubiera sido de esperar a partir del objeto de esta disputa, reflejado en el nombre que se le dio ${ }^{122}$. Es interesante, en cambio, su aceptación implícita de la distinción entre obligaciones de medios y de resultados, que confirma la que hiciera tres años antes en su decisión sobre excepción preliminar del mismo caso ${ }^{123}$. Al señalar que una obligación de negociar solo implica el deber de llegar a un acuerdo cuando las partes han convenido contraer una obligación de resultado, que exige algo más que un mero deber de conducta, la Corte reiteró su jurisprudencia emergente sobre esta materia ${ }^{124}$. Otro aspecto a resaltar de esta decisión judicial es la reaparición de la figura de los acuerdos tácitos. A diferencia de la disputa marítima (Perú c. Chile), donde la Corte la aplicó ex officio en contra de Chile, en el asunto de la obligación de negociar un acceso al Océano Pacífico fue Bolivia quien alegó sin éxito la existencia de este tipo de acuerdos. El hecho que el tribunal volviera a referirse a estos, viene a engrosar un magro listado de casos en los que los ha mencionado, sin mayor explicación respecto a su naturaleza jurídica ${ }^{125}$. Sin perjuicio de lo anterior, donde esta sen-

\footnotetext{
120 Bolivia C. ChILE (2018) párrafo 175.

121 Ver Bolivia C. CHILE (2018) párrafos 91, 97, 106, 116-7, 126, 146-8, 152 \& 158-9.
}

Sobre el derecho de tratados ver en general CorTen y Klein (eds.) (2006); Villiger (2009); y Dörr y SCHMALENBACH (eds.) (2018).

En cuanto a los actos unilaterales ver en general Guerrero Peniche y Rodríguez Cedeño (2003); Goodman (2006); Torres Cazorla (2010); Naime (2012); y Rodríguez Cedeño y Torres Cazorla (2013).

Respecto a los comportamientos recíprocos de los estados ver en general SinClair (1996); DAS (1997); JimÉnEZ (2002); Nuno (2006); y CotTIER y MÜLler (2007).

122 Ver Bolivia C. Chile (2018) párrafos 86-7 \& 91. Ver también López Escarcena (2016) pp. 722-3.

Sobre la obligación de negociar en el derecho internacional ver en general Rogoff (1994); WeLlens (2014); y WeLlens (2016). Ver también OWADA (2008).

123 Ver López Escarcena (2016) pp. 720-2. Ver López Escarcena (2016) pp. 722-4.

Corresponde mencionar que tanto el juez Robinson como el juez ad hoc Daudet rechazaron esta clasificación en sus opiniones disidentes.

Ver Bolivia C. ChILe (2018 juez Robinson) párrafos 78-80; y Bolivia C. ChILE (2018, juez ad hoc Daudet) párrafos 49-55.

El juez Salam, en cambio, la aceptó expresamente en su opinión disidente, calificando la obligación de negociar que según el tendría Chile como de conducta.

Ver BolIVIA C. CHILE (2018, juez Salam) párrafos 27-32.

124 Ver Bolivia C. CHILE (2018) párrafos 87-9. Ver también Hungría C. EsLovaquia (1997) párrafos 135 \& 141; MÉxICO C. EE.UU. (2009) párrafos 17-8, 20, 23, 27 \& 41; ARGENTINA C. URUGUAY (2010) párrafos 146, 187, 205 \& 209; y GEORGIA C. RUSIA (2011) párrafos 157-60.

En cuanto a la distinción entre obligaciones de medios y obligaciones de resultado en el derecho internacional ver SANTUlli (2013) pp. 195-7; y ECONOMides (2010) pp. 372 \& 375.

125 Ver Bolivia C. ChILE (2018) párrafo 97. Ver también NiCARAGUA C. Colombia (2007) párrafo 253; y PERÚ C. CHILE (2014) párrafo 91. Confrontar con TúNEZ/LIBIA (1982) párrafos 95 \& 118; CANAdÁ/EE.UU. (1984) 
tencia sí va a pasar a constituir un hito insoslayable es en las relaciones boliviano-chilenas. Si tras el fallo recaído en su disputa con Chile los peruanos sacaron cuentas alegres, en el caso de Bolivia ha sido todo lo contrario ${ }^{126}$. En un contexto de triunfalismo sordo a toda crítica, la sentencia de fondo en esta controversia no pudo sino caer como un cataclismo en quienes ya estaban pensando en como negociar con Chile una salida soberana al mar, ahora que estaría obligado por un tribunal internacional a hacerlo ${ }^{127}$. Nada permite hoy mitigar el hecho que esta decisión judicial supuso un golpe letal a la centenaria aspiración marítima boliviana. Desde un punto de vista jurídico, la única otra derrota que puede compararse con esta es la que sufrió Bolivia en la Sociedad de las Naciones en $1921^{128}$. Y es que el precio que estuvieron dispuestos a pagar los bolivianos para que la Corte fallara este caso fue muy alto, pues Bolivia aceptó la validez del Tratado de 1904 en sus escritos y alegatos presentados a raíz de la excepción preliminar de incompetencia interpuesta por Chile, dejando así de lado una estrategia casi tan antigua como su aspiración marítima ${ }^{129}$.

¿Por qué perdió Bolivia en La Haya? Hay muchas respuestas posibles para esta pregunta. La falta de claridad en la demanda boliviana es una de ellas. Según esta, ¿tenía Chile una obligación de medios o una de resultados? Sobre este punto, el tribunal ya había distinguido en su decisión sobre excepción preliminar entre lo solicitado por Bolivia (determinar que Chile tiene una obligación de negociar incumplida) del objetivo último buscado por este estado (que le permita acceder con soberanía al Océano Pacífico), señalando expresamente que de llegar a resolver este caso en favor del demandante "no le correspondería a la Corte predeterminar el resultado de cualquier negociación que tenga lugar como consecuencia de dicha obligación”130. A pesar de esto, Bolivia optó por mantener la ambigüedad respecto a este asunto durante el proceso de fondo ${ }^{131}$. Esto, evidentemente no la favoreció, pues ya en los alegatos de la excepción preliminar el juez Owada le había preguntado a Bolivia qué entiende por acceso soberano ${ }^{132}$. El estado demandante no pudo o no quiso responder a esta interpelación con un planteamiento moderno y creativo, siendo que era justamente lo que le pedía de manera implícita a la Corte respecto de importantes nociones del derecho internacional, como los tratados y los actos unilaterales, entre otras: que las interprete de manera progresista, más que evolutiva. Con esta respuesta Bolivia puso en

párrafo 130; CAMERÚN C. NIGERIA (2002) párrafo 303; y MALASIA/SINGAPUR (2008) párrafos 120-1.

Respecto a los acuerdos tácitos ver en general D’Aspremont (2015); y Distefano (2015). Ver también AbugatTÁs (2014); y GaUtier (2016).

126 Para el caso peruano ver en general Sifuentes y Riepl (2014).

127 Ver Aparicio (2019) p. 90; Carrasco (2019) pp. 17-9; Guzmán Escobari (2019) p. 100; y Longaric (2019) pp. $120,121-2 \& 125-7$

128 Ver FERnÁNDEZ (2019) p. 78.

129 Ver Aparicio (2019) pp. 92-3; y Longaric (2019) p. 120. Ver también Longaric (2014) pp. 77, 94-5 \& 97-8.

130 Bolivia C. Chile (2015) párrafo 33. Ver Bolivia C. Chile (2015) párrafo 32. Ver también Longaric (2019) p. 121.

131 Ver Bolivia C. Chile (2018, juez Salam) párrafos 27-31. Confrontar con Bolivia C. ChILE (2018, juez ad hoc Daudet) párrafos 49-51\&53.

132 Ver Bolivia c. Chile (2018) párrafo 90. Ver también GuZmán Escobari (2019) pp. 100-3. 
duda, además, su declaración de no disputar la validez del Tratado de 1904, hecha anteriormente en el mismo juicio ${ }^{133}$.

Pareciera que en definitiva lo esencial de los argumentos presentados por Chile terminó por persuadir a la Corte, la cual escogió dictar una sentencia que no dificulte futuras negociaciones interestatales, y desincentive eventuales demandas por supuestas obligaciones de negociar incumplidas. Como sea, la judicialización del problema de la mediterraneidad de Bolivia probó ser un grueso error de la diplomacia de ese país, que le puso fin a una era de negociaciones con Chile sobre ese asunto ${ }^{134}$. El impacto de la sentencia de la Corte fue tan grande, que en Bolivia se llegó a decir que "[e]l 1 de octubre de 2018 marcó el verdadero final de la Guerra del Pacífico"135. El entonces presidente de Bolivia, Evo Morales, trato de minimizar la durísima derrota sufrida refiriéndose a la sentencia como un informe, en un intento desesperado y burdo de bajarle el perfil al desastre que había provocado y presenciado $^{136}$. De toda la sentencia, él solo recogió el párrafo que dice que "la conclusión de la Corte no debiese ser entendida como un impedimento a las Partes de continuar su diálogo e intercambios, en un espíritu de buena vecindad, para abordar los asuntos relativos a la situación mediterránea de Bolivia, solución que ambos han reconocido es una materia de interés mutuo"137. Pocos días después de volver a Bolivia, Morales le envió una carta al presidente de Chile, Sebastián Piñera, pidiéndole retomar las conversaciones sobre la aspiración marítima de su país. A la fecha, esa carta no ha tenido respuesta formal, y todo indica que no la tendrá en un futuro cercano ni lejano ${ }^{138}$.

\section{CONCLUSIÓN}

El fallo del 1 de octubre de 2018 es una derrota que va a resonar en Bolivia por mucho tiempo. Si bien en Chile también hubo sorpresa, el contraste que se produjo entre la excesiva confianza boliviana y el funesto desenlace de su aventura judicial no pudo ser mayor. Desde un punto de vista teórico, la sentencia de fondo en el asunto de la obligación de negociar un acceso al Océano Pacífico no es de gran interés. Teniendo la posibilidad de pronunciarse sobre aspectos importantes del derecho de tratados y del derecho de los actos

133 Ver Bolivia C. Chile (2015) párrafo 30.

134 Ver Brockmann (2019) p. 36; Oporto (2019) pp. 43-5 \& 47. Ver también Aparicio (2019) pp. 89-97; Brockmann (2019) pp. 33-5 \& 37-9; y Longaric (2019) p. 122.

Cabe señalar que Ramiro Orias fue el primero que propuso, ya en el año 2000, que los ofrecimientos hechos por Chile para conversar con Bolivia sobre una salida al mar constituían un acto unilateral de promesa, que generaba una obligación de negociar. Ver Orías (2019) pp. 129-30. Ver también Longaric (2014) pp. 102-3. Ver en general Orias (2000).

Esta línea argumental tomó particular fuerza en la narrativa doctrinal boliviana en los años posteriores a la decisión sobre excepción preliminar de la Corte, hasta su sentencia de fondo.

Ver en general FERnÁNDEZ (2014); y GUZMÁn ESCOBARI (2015).

135 Brockmann (2019) p. 36. Ver Laserna (2019) p. 39.

136 Ver Salazar (2019) pp. 49-51. Ver también Longaric (2019) p. 126.

137 Bolivia C. CHILE (2018) párrafo 176.

138 Enterado por la prensa de la misiva de Morales, el presidente de Chile invitó a Bolivia a entender el significado del fallo. Ver El Mercurio (10/10/2018) p. C2; y El Mercurio (11/10/2018) p. C4. 
unilaterales, la Corte solo reiteró ciertas nociones fundamentales, sin entrar en detalles. Lo mismo ocurrió respecto del estoppel y de la aquiescencia, e incluso de la obligación de negociar en el derecho internacional, que es donde razonablemente se podría haber esperado algún desarrollo jurisprudencial. Es destacable, en cambio, la distinción que en esta sentencia volvió a hacer implícitamente la Corte entre obligaciones de medios y obligaciones de resultado. No lo es, en tanto, la nueva mención superficial que hizo de los acuerdos tácitos, la cual lejos de aclarar algo en el asunto, lo mantiene en la obscuridad conceptual que ya le es habitual. Sin embargo, donde esta sentencia va a marcar un antes y un después es en las relaciones boliviano-chilenas, que necesariamente debieran tomar ahora un nuevo rumbo, alejado de la discusión soberana. Para complacer una verdadera obsesión nacional, por más de un siglo Chile incluyó la aspiración marítima en sus negociaciones bilaterales con Bolivia, siempre precisando que cualquier diálogo a este respecto quedaba supeditado al respeto irrestricto de lo establecido en el Tratado de 1904. Aparentemente, esta ubicua mención nunca se entendió en el mismo sentido a ambos lados de la frontera que fijó dicho acuerdo internacional. Es hora de ser más claros. Para evitar que en el futuro una redacción ambigua o un fraseo equivocado pueda ser interpretado como una promesa o incluso un tratado, si las circunstancias que la rodean así lo permiten, Chile tiene que excluir la aspiración marítima soberana de Bolivia de la tabla de temas a discutir bilateralmente, como política de estado. Esto no quiere decir que no se pueda mejorar la integración boliviano-chilena. Facilitar la salida al mar de Bolivia por los puertos del norte de Chile va en beneficio de todos, pero seguir anclados en discusiones decimonónicas no ayuda a nadie.

Como dijo la Corte ese 1 de octubre, Bolivia y Chile tienen que seguir conversando. Y lo tienen que hacer por la sencilla razón de que son vecinos, y de que lo seguirán siendo mientras existan ambos estados. Se puede negociar de todo, pero nunca más sobre soberanía, a menos que se quiera volver a La Haya a escuchar a otros bien pagados abogados desempolvar antiguas negociaciones, que parten nada menos que en las décadas inmediatamente posteriores al fin de la Guerra del Pacífico y recurren gran parte del siglo XX. Quizás sacando la soberanía de la mesa de negociaciones, Bolivia pueda superar su prolongado estado de negación colectiva y asumir de una vez por todas que acordó libremente dejar de tener costa en el Océano Pacífico hace ya más de 100 años, para salir al mundo por puertos chilenos. Lejos de enfrentarnos, lo acordado por Bolivia y Chile en 1904 sigue ofreciendo una inmejorable oportunidad para alcanzar una integración bilateral verdadera. La sentencia de la Corte no hace otra cosa que recordarnos esto.

\section{BIBLIOGRAFÍA CITADA}

Abugattás, Gattas (2014): "Análisis sobre la referencia a los acuerdos tácitos en algunos casos sobre delimitación marítima, con especial atención al asunto de la delimitación marítima entre Perú y Chile", Agenda Internacional, vol. 21, No 32: pp. 79-105.

Aparicio, Jaime (2019): "El populismo jurídico y el descalabro diplomático y político en La Haya”, en Oporto, Henry (ed.), Bolivia en La Haya: lecciones de la demanda contra Chile (La Paz, Bolivia, Plural Editores) pp. 89-97. 
Benadava, Santiago (1993): Historia de las fronteras de Chile (Santiago, Chile, Editorial Universitaria).

Brockmann, Roberto (2019): "Ha terminado la guerra", en Oporto, Henry (ed.), Bolivia en La Haya: lecciones de la demanda contra Chile (La Paz, Bolivia, Plural Editores) pp. 33-8.

Bustos, Carlos (2004): Chile y Bolivia. Un largo camino. De la independencia a Monterrey (Santiago, Chile, RIL Editores).

Bustos, Carlos (2018): Diplomacia chilena. Una perspectiva histórica (Santiago, Chile, RIL Editores).

Carrasco, Carlos Antonio (2019): “¿Qué pasó en La Haya?”, en Oporto, Henry (ed.), Bolivia en La Haya: lecciones de la demanda contra Chile (La Paz, Bolivia, Plural Editores) pp. 17-9.

Cluny, Claude Michel (2000): Atacama: essai sur la Guerre du Pacifique 1879-1883 (París, Francia, Éditions de la Différence).

Concha, José Miguel (2011): Iniciativas chilenas para una alianza estratégica con Bolivia (1879-1899) (La Paz, Bolivia, Plural Editores).

Concha, José Miguel, y GaraY, Cristián (2013): El tratado de 1904: negociaciones e intereses involucrados (La Paz, Bolivia, Plural Editores).

Corten, Olivier, y Klein, Pierre (eds.) (2006): Les Conventions de Vienne sur le Droit des Traités. Commentaire article par article, vols. 1-3 (Bruselas, Bélgica, Éditions Bruylant).

CotTier, Thomas, y Müller, Jörg Paul (2007): “Estoppel”, en Wolfrum, Rüdiger (ed.), Max Planck Encyclopedia of Public International Law (Oxford, Reino Unido, Oxford University Press).

Das, Hans (1997): "Estoppel et l'acquisescement assimilations pragmatiques et divergences conceptuelles", Revue Belge de Droit International, vol. 30, No 2: pp. 607-34.

D'Aspremont, Jean (2015): "The International Court of Justice and Tacit Conventionality", Questions of International Law, vol. 18: pp. 3-17.

Distefano, Giovanni (2015): "L'accord tacite ou l'univers parallèle du droit des traités", Questions of International Law, vol. 18: pp. 17-37.

Dörr, Oliver, y Schmalenbach, Kirsten (eds.) (2018): Vienna Convention on the Law of Treaties: A Commentary (Berlín, Alemania, Springer Verlag).

Durán, Phillip (2014): La hora de los halcones: la trastienda del conflicto Chile-Perú en La Haya (Santiago, Chile, Editorial Planeta).

EConomides, Constantin (2010): "Content of the Obligation: Obligations of Means and Obligations of Result”, en Crawford, James, Pellet, Alain, y Olleson, Simon (eds.), The Law of International Responsibility (Nueva York, EE.UU., Oxford University Press) pp. 371-81.

Errázuriz, Hernán Felipe, y Neri, Fabio (2019): Bolivia vs. Chile en La Haya: obligación de negociar una salida al Océano Pacífico (Santiago, Chile, Consejo Chileno para las Relaciones Internacionales).

Farcau, Bruce (2000): Chile, Peru, and Bolivia in the War of the Pacific, 1879-1884 (Westport, EE.UU., Praeger Publishers). 
Fernández, Gustavo (2019): "Quien llevaba el estandarte era él, pero el golpe no le afecta solo a él”, en Oporto, Henry (ed.), Bolivia en La Haya: lecciones de la demanda contra Chile (La Paz, Bolivia, Plural Editores) pp. 77-83.

Fernández, Sergio Alberto (2014): Promissio est servanda. Lo que se promete se cumple: la reintegración marítima en la política exterior boliviana, desde sus inicios hasta la demanda ante La Haya (La Paz, Bolivia, Plural Editores).

FigueroA, Uldaricio (2007): La demanda maritima boliviana en los foros internacionales (Santiago, Chile, RIL Editores).

Gautier, Philippe (2016): “Conduite, accord tacite et délimitation maritime”, en D’ArGENT, Pierre, Lagrange, Evelyne, y Oeter, Stefan (eds.), Droit des frontiers internationales / The Law of International Borders (París, Francia, Éditions A. Pedone) pp. 145-61.

Goodman, Camille (2006): "Acta Sunt Servanda - A Regime for Regulating the Unilateral Acts of States at International Law”, Australian Year Book of International Law, vol. 25, No 1: pp. 43-73.

Guerrero Peniche, Nicolás, y Rodríguez Cedeño, Víctor (2003): "Los actos unilaterales de los estados en derecho internacional: los trabajos de codificación en la Comisión de Derecho Internacional”, Anuario Mexicano de Derecho Internacional, vol. 3: pp. 195-223.

GuZmán Escobari, Andrés (2019): “Oportunidad perdida”, en Oporto, Henry (ed.), Bolivia en La Haya: lecciones de la demanda contra Chile (La Paz, Bolivia, Plural Editores) pp. 99-107.

GUZMÁN EsCOBARI, Andrés (2015): Un mar de promesas incumplidas: la historia del problema maritimo boliviano (1879-2015) (La Paz, Bolivia, Plural Editores).

Infante, Demetrio (2014): Confidencias limeñas: Charaña, espionaje y algo más (Santiago, Chile, Editorial Catalonia).

Infante, María Teresa (2016): "Latin America and the International Court of Justice: The Pact of Bogotá", en Wojcikiewicz Almeida, Paula y Sorel, Jean-Marc (eds.), Latin America and the International Court of Justice: Contributions to International Law (Abingdon, Reino Unido, Routledge) pp. 61-73.

Infante, María Teresa (2017): “The Pact of Bogotá: Cases and Legal Challenges”, Anuario Colombiano de Derecho Internacional, vol. 10: pp. 85-116.

JiMÉNEZ, Francisco (2002): Los comportamientos reciprocos en derecho internacional: a propósito de la aquiescencia, el estoppel y la confianza legitima (Madrid, España, Editorial Dilex).

Lagos Erazo, Jaime (2013): Las aspiraciones maritimas de Bolivia (Santiago, Chile RIL Editores).

Lagos Erazo, Jaime (2016): La aspiración maritima de Bolivia ¿Obligación de negociar? (Santiago, Chile, RIL Editores).

Laserna, Roberto (2019): “¿Por qué fracasamos?”, en Oporto, Henry (ed.), Bolivia en La Haya: lecciones de la demanda contra Chile (La Paz, Bolivia, Plural Editores) pp. 39-42.

LirA, Diego (2009): Aspectos jurídicos de las aspiraciones maritimas bolivianas (Santiago, Chile, Editorial Puerto de Palos).

Longaric, Karen (2019): "Reseña del proceso contra Chile sobre la obligación de negociar”, en Oporto, Henry (ed.), Bolivia en La Haya: lecciones de la demanda contra Chile (La Paz, Bolivia, Plural Editores) pp. 119-27. 
LONGARIC, Karen (2014): Solución pacifica de conflictos entre estados. Conceptos y estudio de casos en América Latina (La Paz, Bolivia, Programa de Investigación Estratégica).

López EsCARCEna, Sebastián (2014a): Indirect Expropriation in International Law (Cheltenham, Reino Unido, Edward Elgar Publishing).

López Escarcena, Sebastián (2014b): "La disputa marítima entre Perú y Chile. Comentario de la sentencia de la Corte Internacional de Justicia, de fecha 27 de enero de 2014”, Revista Chilena de Derecho, vol. 41, No 3: pp. 1133-53.

López Escarcena, Sebastián (2016): "El asunto de la obligación de negociar un acceso al Océano Pacífico. Comentario de la decisión sobre excepción preliminar de la Corte Internacional de Justicia, de fecha 24 de septiembre de 2015", Revista Chilena de Derecho, vol. 43, No 2: pp. 715-34.

MAYER, Alberto (2018): El tratado de 1904: cuando Bolivia no tuvo mejor opción (Santiago, Chile, Editorial Legatum).

Millar, René (2005): Pasión de servicio. Julio Philippi Izquierdo (Santiago, Chile, Ediciones UC).

Naime, Mónica (2012): "El final de la espiral del caos: la regulación de los actos jurídicos unilaterales de los Estados", Anuario Mexicano de Derecho Internacional, vol. 12: pp. 631-72.

Nuno, Sérgio Marques Antunes (2006): “Acquiescence”, en Wolfrum, Rüdiger (ed.), Max Planck Encyclopedia of Public International Law (Oxford, Reino Unido, Oxford University Press).

Oporto, Henry (2019): "El mar: fin de un mito", en Oporto, Henry (ed.), Bolivia en La Haya: lecciones de la demanda contra Chile (La Paz, Bolivia, Plural Editores) pp. 43-8.

ORIAS, Ramiro (2000): "El derecho internacional y las negociaciones marítimas con Chile", en Zelada, Alberto (ed.), Bolivia: temas de la agenda internacional (La Paz, Bolivia, Ministerio de Relaciones Exteriores y Culto) pp. 371-85.

Orias, Ramiro (2019): “¿Qué nos pasó en La Haya?”, en Oporto, Henry (ed.), Bolivia en La Haya: lecciones de la demanda contra Chile (La Paz, Bolivia, Plural Editores) pp. 129-32.

OwadA, Hisashi (2008): "Pactum de contrahendo, pactum de negotiando", en Wolfrum, Rüdiger (ed.), Max Planck Encyclopedia of Public International Law (Oxford, Reino Unido, Oxford University Press).

Pinochet de la Barra, Oscar (2004): Chile y Bolivia: ;hasta cuándo! (Santiago, Chile, Lom Ediciones).

Rodríguez Cedeño, Víctor, y Torres Cazorla, María Isabel (2013): "Unilateral Acts of State in International Law”, en Wolfrum, Rüdiger (ed.), Max Planck Encyclopedia of Public International Law (Oxford, Reino Unido, Oxford University Press).

Rodríguez Elizondo, José (2014): Historia de dos demandas: Perú y Bolivia contra Chile (Santiago, Chile, El Mercurio-Aguilar).

Rodríguez Elizondo, José (2016): Todo sobre Bolivia y la compleja disputa por el mar (Santiago de Chile, Ediciones El Mercurio).

Rodríguez Guarachi, Eduardo (2015): "Reflexiones sobre la relación bilateral. La demanda de Bolivia contra Chile", Anuario de Derecho Público 2015: Universidad Diego Portales: pp. 405-17. 
Rogoff, Martin (1994): “The Obligation to Negotiate in International Law: Rules and Realities", Michigan Journal of International Law, vol. 16, No 1: pp. 141-85.

Salazar, Fernando (2019): "El fallo de La Haya, sofismas y mitomanía”, en OporTo, Henry (ed.), Bolivia en La Haya: lecciones de la demanda contra Chile (La Paz, Bolivia, Plural Editores) pp. 49-51.

SANTULLI, Carlo (2013): Introduction au droit international: formation - application - exécution (París, Francia, Éditions A. Pedone).

Sater, William (2007): Andean Tragedy. Fighting the War of the Pacific, 1879-1884 (Lincoln, EE.UU., University of Nebraska Press).

Sifuentes, Marco, y Riepl, Martín (2014): El último cartucho. Cómo ganamos 50.000 km² de mar en la corte de la Haya (Lima, Perú, Editorial Planeta).

Sinclair, Ian (1996): "Estoppel and Acquiescence", en Lowe, Vaughan, y FitzMaurice, Malgosia (eds.), Fifty Years of the International Court of Justice Essays in Honour of Sir Robert Jennings (Cambridge, Reino Unido, Cambridge University Press) pp. 104-20.

TAPIA VAldés, Jorge, y Mardones, Luciano (2011): La mediterraneidad de Bolivia y el factor peruano (Santiago, Chile, Editorial Jurídica de Chile).

Torres Cazorla, María Isabel (2010): Los actos unilaterales de los estados (Madrid, España, Editorial Tecnos).

Valencia-Ospina, Eduardo (2011): "Bogotá Pact (1948)", en Wolfrum, Rüdiger (ed.), Max Planck Encyclopedia of Public International Law (Oxford, Reino Unido, Oxford University Press).

Villiger, Mark (2009): Commentary on the 1969 Vienna Convention on the Law of Treaties (Leiden, Países Bajos, Martinus Nijhoff Publishers).

Wellens, Karel (2014): Negotiations in the Case Law of the International Court of Justice (Farnham, Reino Unido, Ashgate Publishing).

Wellens, Karel (2016): "Obligation to Negotiate", en Wojcikiewicz Almeida, Paula, y Sorel, Jean-Marc (eds.), Latin America and the International Court of Justice: Contributions to International Law (Abingdon, Reino Unido, Routledge) pp. 77-87.

\section{INSTRUMENTOS CITADOS}

Tratado de Paz y Amistad entre Chile y Perú, Lima (20 de octubre de 1883).

Tratado de Paz, Amistad y Comercio entre Bolivia y Chile, Santiago (20 de octubre de 1904).

Tratado entre Chile y Perú, Lima (3 de junio de 1929).

Carta de la ONU, San Francisco (26 de junio de 1945).

CARTA DE LA OEA, Bogotá (30 de abril de 1948).

Tratado Americano de Soluciones Pacíficas, Bogotá (30 de abril de 1948).

Tratado sobre la No Proliferación de las Armas Nucleares, Londres, Moscú y Washington (1 de julio de 1968).

Convención de Viena sobre el Derecho de los Tratados, Viena (23 de mayo de 1969). 


\section{JURISPRUDENCIA CITADA}

Trafico ferroviario entre Lituania y Polonia (1931): Corte Permanente de Justicia Internacional, 15 de octubre de 1931 (opinión consultiva).

Plataforma continental del Mar del Norte, Alemania C. Dinamarca, y Alemania C. Países BAJOS (1969): Corte Internacional de Justicia, 20 de febrero de 1969 (sentencia de fondo).

Ensayos nuCleares, Australia C. Francia (1974): Corte Internacional de Justicia, 20 de diciembre de 1974 (sentencia de fondo).

Ensayos nucleares, Nueva Zelanda C. FRancia (1974): Corte Internacional de Justicia, 20 de diciembre de 1974 (sentencia de fondo).

Plataforma continental del Mar Egeo, GReCIA C. Turquía (1978): Corte Internacional de Justicia, 19 de diciembre de 1978 (sentencia de fondo).

Plataforma continental, Túnez/Libia (1982): Corte Internacional de Justicia, 24 de febrero de 1982 (sentencia de fondo).

DELIMITACión de LA FRONTERA MARÍtima en EL GOLFO dE MAINE, CANAdÁ/EE.UU. (1984): Corte Internacional de Justicia, 12 de octubre de 1984 (sentencia de fondo).

DisPutA TERRITORIAL, INSULAR Y MARÍTIMA, EL SALVADOR/HONDURAS (1990): Corte Internacional de Justicia, 13 de septiembre de 1993 (decisión sobre la aplicación de Nicaragua para intervenir).

DelimitaCión MARÍtIMA Y CUESTIONES TERRITORIALES, QATAR C. BAHREIN (1994): Corte Internacional de Justicia, 1 de julio de 1994 (decisión sobre jurisdicción y admisibilidad).

LEGALIDAD DE LA AMENAZA O DEL USO DE ARMAS NUCLEARES (1996): Corte Internacional de Justicia, 8 de julio de 1996 (opinión consultiva).

Proyecto Gabćĺ́xono-Nagymaros, Hungría c. Eslovaquia: Corte Internacional de Justicia, 25 de septiembre de 1997 (sentencia de fondo).

Disputa SOBRE LA FRONTERA TERRESTRE Y MARÍTIMA, CAMERÚN C. NigERIA (1998): Corte Internacional de Justicia, 11 de junio de 1998 (decisión sobre excepciones preliminares).

Disputa sobre LA FRONTERA terRestre Y MARÍtima, CAMERÚN C. Nigeria, GUiNEA ECUATORIAL INTERVINIENDO (2002): Corte International de Justicia, 10 de octubre de 2002 (sentencia de fondo).

Actividades armadas en el territorio del Congo, Congo C. Ruanda (2006): Corte Internacional de Justicia, 3 de febrero de 2006 (decisión sobre jurisdicción y admisibilidad).

Disputa territorial y marítima, Nicaragua C. Honduras (2007): Corte Internacional de Justicia, 8 de octubre de 2007 (sentencia de fondo).

Soberanía sobre Pedra Branca/Pulau Batu Puteh, Middle Rocks y South Ledge, Malasia/SinGAPUR (2008): Corte Internacional de Justicia, 23 de mayo de 2008 (sentencia de fondo).

Avena Y otros naCionales meXicanos, MÉXICO C. EE.UU. (2009): Corte Internacional de Justicia, 19 de enero de 2009 (decisión sobre interpretación).

Plantas de celulosa sobre el río URUGUay, Argentina C. URUGUay (2010): Corte Internacional de Justicia, 20 de abril de 2010 (sentencia de fondo).

Aplicación de la Convención Internacional para la Eliminación de Todas las Formas de Discriminación Racial, GEORGIA C. Rusia (2011): Corte Internacional de Justicia, 1 de abril de 2011 (decisión sobre excepción preliminar). 
AplicaCión del aCUERDo provisional de 13 de septiembre de 1995, MaCEDONIA C. GRECIA (2011): Corte Internacional de Justicia, 5 de diciembre de 2011 (sentencia de fondo).

Disputa marítima, Perú c. Chile (2014): Corte Internacional de Justicia, 27 de enero de 2014 (sentencia de fondo).

Obligación de negociar un acceso al Océano Pacífico, Bolivia C. Chile (2015): Corte Internacional de Justicia, 24 de septiembre de 2015 (decisión sobre excepción preliminar).

Obligación de negociar un acceso al OcÉano Pacífico, Bolivia C. Chile (2018): Corte Internacional de Justicia, 1 de octubre de 2018 (declaración del juez Abdulqawi Ahmed Yusuf).

Obligación de negociar un acceso al OcÉano Pacífico, Bolivia C. Chile (2018): Corte Internacional de Justicia, 1 de octubre de 2018 (opinión disidente del juez ad hoc Yves Daudet).

Obligación de negociar un acceso al Océano Pacífico, Bolivia C. Chile (2018): Corte Internacional de Justicia, 1 de octubre de 2018 (opinión disidente del juez Patrick Robinson).

Obligación de negociar un acceso al Océano Pacífico, Bolivia C. Chile (2018): Corte Internacional de Justicia, 1 de octubre de 2018 (opinión disidente del juez Nawaf Salam).

Obligación de negociar un acceso al OcÉano Pacífico, Bolivia C. Chile (2018): Corte Internacional de Justicia, 1 de octubre de 2018 (sentencia de fondo). 
